Lepr Rev (2000) 71, 369-376

\title{
Towards an understanding of non-compliance. An assessment of risk factors for defaulting from leprosy treatment
}

\author{
M.L. HEYNDERS*, J.J. MEIJS* \& A.M. ANDERSON** \\ *Almalaan 6, 3431 GX Nieuwegein, The Netherlands \\ **INF RELEASE, PO Box 28, Pokhara, Nepal
}

Accepted for publication 16 June 2000

\begin{abstract}
Summary Within the Eastern Leprosy Control Project of Nepal, a retrospective case control study looked for simple factors that might be used operationally to predict non-compliant behaviour in patients. Patients with these factors would then become the targets of measures such as intensified health education messages and home visits in order to reduce the risk of defaulting. A study of 1442 patient cards (half defaulters, half treatment completed) revealed occasional small but significant demographic and clinical differences, but none was of a sufficient magnitude to be operationally useful. Review of the attendance of patients in the first few months of treatment suggested that eventual defaulting was strongly associated with irregularity from the commencement of treatment. It is possible that an early indicator based on attendance over the first months can be used to target patients who are in danger of non-completion of treatment.
\end{abstract}

\section{Introduction}

In the Eastern Leprosy Control Project of Nepal, the defaulter rate is high. Based on the 1996/ 1997 cohort of newly registered patients, $42 \%$ of $\mathrm{PB}$ and $48 \%$ of $\mathrm{MB}$ patients failed to complete treatment within the time limits set by WHO ( 9 months for PB, 36 months for MB at that time). A programme was in place to try to reduce the defaulter rate, and increase the treatment completion rate to the national target of $85 \%$ set by His Majesty's Government of Nepal. The programme included identification of patients who were late for appointments followed by sending of reminder letters, and eventually a home visit. There was no apparent improvement resulting from this programme.

This retrospective study was undertaken to try to identify any commonality in patients who eventually default, based on the information readily available on the patient registration/ treatment card. Such commonality, if found, would be of value to target resources such as health education and counselling to prevent defaulting.

Correspondence to: M.L. Heynders, Almalaan 6, 3431 GX Nieuwegein, The Netherlands (e-mail: heynders@csi.com)

Dr Heynders is a Doctoral Researcher at the South Bank University, London. Dr Meijs was formerly an NLR-ELCP project leader. 
The study had two main objectives: (i) to examine potential risk factors for noncompliance so that patients at risk of becoming a defaulter can be identified at registration; and (ii) using the clinic attendance pattern, to try to find an early indicator that will identify patients who will become defaulters, whilst they are still in contact with the clinic.

\title{
Materials and methods
}

\author{
SELECTION OF VARIABLES
}

A literature review suggested that defaulting, irregularity and non-compliance have been attributed to a variety of causes. Since this study was to be retrospective, the variables available for study were limited to those recorded on the patient treatment card. Only those variables recorded on the Nepal patient treatment card, and previously shown to be significant by another author, were used as the basis for this study. ${ }^{1,4,5,6,8-12}$

The possible variables were reviewed and placed into five groups:

1. Simple demographic variables: age, gender, distance of home from treatment centre and leprosy in the family.

2. Seasonal variables: month of registration.

3. Variables relating to clinical condition at registration, presence of a visible patch on the face and presence of visible impairment (as measured by WHO disability grade).

4. Variables related to treatment history: previous treatment with dapsone monotherapy.

5. Variables related to pattern of attendance after registration: total number of visits made, number of visits in first 2 months, number of visits in first 3 months, number of visits in first 4 months and number of visits in first 6 months.

DEFINITIONS

$P B / M B$

In Nepal, patients are classified PB if only one body area is affected with skin patches or enlarged nerves. MB patients have two or more affected body areas. ${ }^{2,3}$

$M D T$

Multi-drug therapy (MDT) is according to the WHO regimen. PB patients received six doses. MB patients received 24 doses at the time of the cohort under study (WHO MDT regimen 1982-1998). A patient is released from treatment (RFT) if they completed six doses in 9 months (PB) or 24 doses in 36 months (MB).

\section{Defaulter}

A defaulter is a patient who can no longer complete the MDT regimen, regardless of whether $\mathrm{s} /$ he is still coming to the treatment centre. An MB patient becomes a defaulter as soon as they have missed 13 months of treatment. A PB patient is a defaulter when they have missed 4 months of treatment. ${ }^{2}$ 


\section{Dapsone monotherapy}

Some patients in the study received dapsone only, prior to the start of MDT. It was a policy to give a newly registered patient dapsone for 2-3 months to see if they would take treatment regularly, and only if regular on dapsone would they be transferred to MDT. This policy no longer applies in Nepal, but affects some of the patients in the cohort under study.

CHOICE OF COHORT

At the time of the study, PB patients registering in the Nepali year equivalent to 1994/1995, were at least 9 months after registration. MB patients registering in 1992/1993 were 36 months after registration. These cohorts were the most recent groups of patients who could have completed treatment, and were chosen for the study. Cases (defaulters) were those who had failed to complete the WHO regimen of MDT. Controls (RFT) were patients who had completed the WHO regimen within the time limit. The study was restricted to patients registering for the first time at Biratnagar sub-regional referral centre. Patients who transferred into the treatment centre after starting treatment elsewhere, and patients who transferred out to complete treatment at another centre, were excluded from the study.

\section{SAMPLING}

The size of the study was restricted by the number of patient treatment cards available. Since the study area is on the border with India, both Nepali and Indian patients are registered for treatment. The defaulting rate is different for the two groups of patients and the study was to be stratified for stated country of domicile. For Nepali patients all available cards for the defined cohort were used. For Indian patients a simple random sample was drawn (250 each defaulters/RFT).

\section{DATA COLLECTION}

All the required data were tabulated directly from the patient cards. Distance from the treatment centre was measured using a score for each possible village, combining distance, availability of public transport and cost. Visits to the treatment centre were defined as any visit by the patient, either to collect MDT of for any other follow-up. Visits made on behalf of the patient (proxy visits) of by health workers to the patient's home, were excluded.

\section{DATA ANALYSIS}

Data were processed using EPI INFO (6.04). The data were stratified for type of leprosy (MB/ $\mathrm{PB}$ ) and country of domicile (Nepal/India). For binary variables, odds ratios (and their 95\% confidence intervals) were calculated. For multilevel variables, a $\chi^{2}$ test for trend was used. For assessment of the visiting pattern, the number of patients NOT meeting the set criteria (e.g. two out of the first two visits) was taken as presence of the attribute; the number meeting the criteria was absence. Sensitivity, specificity, positive and negative predictive values were calculated as if the indicator was being used to judge the benefit of intervention. 


\section{Results}

Table 1 gives the data for the variables available at registration. Table 2 shows the results for variables calculated from the pattern of attendance in the first few months of treatment.

\section{DEMOGRAPHIC VARIABLES}

In only one case (gender in Indian MB patients) was there any evidence of a difference between patients who became RFT and those who defaulted. There is some evidence $(\mathrm{OR}=0.58,95 \% \mathrm{CI}=0.38-0.98)$ that Indian MB patients who are male default less than females.

SEASONAL VARIABLES

There is no evidence, in any of the subgroups, that the time of year of registration affects compliance.

\section{CLINICAL CONDITION}

For neither variable (facial patch, visible impairment) was there consistent evidence of an

Table 1. Data for the variables available at registration

\begin{tabular}{|c|c|c|c|c|c|}
\hline & & $\begin{array}{c}\text { PB } \\
\text { Nepali }\end{array}$ & $\begin{array}{l}\mathrm{MB} \\
\text { Indian }\end{array}$ & Nepali & Indian \\
\hline $\begin{array}{l}\text { Demographic } \\
\text { Age } \\
<15 \text { years } \\
\geq 15 \text { years }\end{array}$ & $\begin{array}{l}\text { Odds, } \\
\text { ratio } \\
95 \% \text { CI }\end{array}$ & $\begin{array}{c}1 \cdot 21 \\
0 \cdot 59-2 \cdot 47\end{array}$ & $\begin{array}{c}1 \cdot 14 \\
0 \cdot 66-1 \cdot 98\end{array}$ & $\begin{array}{c}1 \cdot 16 \\
0 \cdot 41-3 \cdot 31\end{array}$ & $\begin{array}{c}1 \cdot 19 \\
0 \cdot 61-2 \cdot 33\end{array}$ \\
\hline $\begin{array}{l}\text { Gender } \\
\text { Male } \\
\text { Female }\end{array}$ & $\begin{array}{l}\text { Odds, } \\
\text { ratio } \\
95 \% \text { CI }\end{array}$ & $\begin{array}{l}1 \cdot 12 \\
0 \cdot 67-1 \cdot 89\end{array}$ & $\begin{array}{c}0 \cdot 81 \\
0 \cdot 56-1 \cdot 18\end{array}$ & $\begin{array}{c}1 \cdot 59 \\
0 \cdot 81-3 \cdot 14\end{array}$ & $\begin{array}{c}0 \cdot 58 \\
0 \cdot 38-0 \cdot 98\end{array}$ \\
\hline Distance (4 levels) & $\chi^{2}$ test, $P$ & $0 \cdot 98$ & $0 \cdot 29$ & $0 \cdot 15$ & $0 \cdot 002$ \\
\hline $\begin{array}{l}\text { Leprosy in family } \\
\text { Yes } \\
\text { No }\end{array}$ & $\begin{array}{l}\text { Odds, } \\
\text { ratio } \\
95 \% \text { CI }\end{array}$ & $\begin{array}{c}0 \cdot 52 \\
0 \cdot 22-1 \cdot 23\end{array}$ & $\begin{array}{c}0 \cdot 89 \\
0 \cdot 50-1 \cdot 56\end{array}$ & $\begin{array}{c}1 \cdot 57 \\
0 \cdot 58-4 \cdot 28\end{array}$ & $\begin{array}{c}1 \cdot 09 \\
0 \cdot 67-1 \cdot 78\end{array}$ \\
\hline $\begin{array}{l}\text { Seasonal } \\
\text { Month of registration (12 levels) }\end{array}$ & $\chi^{2}$ test, $P$ & 0.40 & $0 \cdot 28$ & $0 \cdot 86$ & $0 \cdot 31$ \\
\hline $\begin{array}{l}\text { Clinical } \\
\text { Facial patch } \\
\text { Yes } \\
\text { No }\end{array}$ & $\begin{array}{l}\text { Odds, } \\
\text { ratio } \\
95 \%\end{array}$ & $\begin{array}{c}1 \cdot 09 \\
0 \cdot 59-2 \cdot 02\end{array}$ & $\begin{array}{c}1 \cdot 48 \\
0 \cdot 90-2 \cdot 44\end{array}$ & $\begin{array}{c}0 \cdot 56 \\
0 \cdot 30-1 \cdot 05\end{array}$ & $\begin{array}{c}0 \cdot 87 \\
0 \cdot 60-1 \cdot 26\end{array}$ \\
\hline WHO disability grade 3 levels & $\chi^{2}$ test, $P$ & $0 \cdot 14$ & $0 \cdot 43$ & 0.05 & $0 \cdot 44$ \\
\hline $\begin{array}{l}\text { History } \\
\text { Prior dapsone } \\
\text { Yes } \\
\text { No }\end{array}$ & $\begin{array}{l}\text { Odds, } \\
\text { ratio } \\
95 \% \mathrm{CI}\end{array}$ & N/A & N/A & $\begin{array}{c}0 \cdot 46 \\
0 \cdot 25-0 \cdot 87\end{array}$ & $\begin{array}{c}0 \cdot 68 \\
0 \cdot 46-1 \cdot 02\end{array}$ \\
\hline
\end{tabular}


Table 2. Results for variables calculated from the pattern of attendance in the first few months of treatment

\begin{tabular}{|c|c|c|c|c|}
\hline Visiting pattern & & $\mathrm{PB}$ & MB & ALL \\
\hline \multirow[t]{2}{*}{2 out of first 2} & Sensitivity & $45 \%$ & $30 \%$ & $38 \%$ \\
\hline & $\begin{array}{l}\text { Positive } \\
\text { predictive value }\end{array}$ & $86 \%$ & $76 \%$ & $82 \%$ \\
\hline \multirow[t]{2}{*}{3 out of first 3} & Sensitivity & $68 \%$ & $48 \%$ & $58 \%$ \\
\hline & $\begin{array}{l}\text { Positive } \\
\text { predictive value }\end{array}$ & $82 \%$ & $71 \%$ & $78 \%$ \\
\hline \multirow{2}{*}{4 out of first 4} & Sensitivity & $84 \%$ & $59 \%$ & $72 \%$ \\
\hline & $\begin{array}{l}\text { Positive } \\
\text { predictive value }\end{array}$ & $78 \%$ & $69 \%$ & $74 \%$ \\
\hline \multirow[t]{2}{*}{6 out of first 6} & Sensitivity & & $79 \%$ & \\
\hline & $\begin{array}{l}\text { Positive } \\
\text { predictive value }\end{array}$ & & $65 \%$ & \\
\hline \multirow[t]{2}{*}{2 out of first 3} & Sensitivity & $39 \%$ & $16 \%$ & $28 \%$ \\
\hline & $\begin{array}{l}\text { Positive } \\
\text { predictive value }\end{array}$ & $98 \%$ & $92 \%$ & $96 \%$ \\
\hline \multirow[t]{2}{*}{3 out of first 4} & Sensitivity & $63 \%$ & $32 \%$ & $49 \%$ \\
\hline & $\begin{array}{l}\text { Positive } \\
\text { predictive value }\end{array}$ & $96 \%$ & $89 \%$ & $94 \%$ \\
\hline
\end{tabular}

effect on compliance. For both variables one of the four subgroups shows a significant or borderline significant effect, but there is no consistent pattern.

\section{TREATMENT HISTORY}

Previous treatment with dapsone monotherapy results in significantly fewer defaulters in the Nepali group, and is borderline significant in the Indian group.

\section{PATTERN OF ATTENDANCE}

For PB patients, the median number of visits made by defaulters was two $\left(25^{\text {th }} / 75^{\text {th }}\right.$ centile $1-3)$. For MB patients, this figure rose to seven (4-13). There were no significant differences between Nepalis and Indians.

As would be expected, the later in the treatment regimen that the pattern of attendance is calculated, the better the predictive nature. However, all of the patterns selected for study were associated with significant risk of becoming a defaulter.

\section{Discussion}

A previously reported study ${ }^{8}$ found that women tend to be less compliant than men. This was found in only one group of our study (Indian MB patients), and may result from the reduced freedom to move outside the house unescorted. The Purdah system is observed more in the Indian states bordering Nepal than in Nepal itself. The greater number of visits required for 
MB treatment, and the minimal symptoms associated with PB type disease, may be reasons why this effect is noted only in MB patients. In terms of accessibility, this study suggests that Indian men are more compliant when they come a greater distance to the treatment centre. This is in direct contrast to other studies ${ }^{7,10}$ where good accessibility was positively related to compliance. There is a difference between the requirement to travel a great distance because treatment is not locally available, and the choice to travel either for improved facilities, or because of the fear of being recognized in one's own community. If the patients in this study are travelling out of choice, then this could be expected to be reflected in good motivation, and therefore explain these findings.

In general, however, despite being selected as potential indicators on the basis of prior published research, none of the demographic, seasonal or clinical indicators show a consistent or large enough effect to be suitable indicators to enable targeting of messages or activities aimed at enhancing compliance.

Prior dapsone therapy appears to be associated with reduced defaulting dapsone was given for 2 or 3 months, and only those patients compliant on dapsone therapy were registered for MDT. The underlying reasoning was that MDR would be reduced. Since the median number of visits for PB defaulters is just two, the pretreatment had the effect of ensuring that many non-compliant patients defaulted before MDT started. The observed effect of prior dapsone therapy is therefore likely to be due to the fact that it was given for two or three visits before MDT registration and not a reflection of the drug treatment, or any reduced compliance with MDT.

It is clear that none of the variables recorded at registration are operationally useful in predicting patients who are at risk of defaulting. Based on the information about visits to the clinic, the time available to give any message targeted at reducing defaulting is very short, including time left for Health Education. Only 50\% of PB patients who default make two visits to the clinic, whilst $50 \%$ of $\mathrm{MB}$ defaulters make at least seven visits. These findings suggest that prospective, qualitative studies about the patient's first visit to the treatment centre and their experience with treatment, may be of value in understanding noncompliance. Review of the potential early indicators based on attendance patterns reinforces the issue of the few visits that defaulters seem to make. Maybe the length of the treatment, the need to work, particularly, in rural communities, at certain times of the year, or the increased risk of exposure in the community with multiple visits, are the source of non-compliant behaviour.

In this study, patients who did not take at least two out of the first three MDT doses on time, would have been a reasonable sub group to target to try to prevent defaulting, either at their next visit, or by home visit/letter. The positive predictive value overall is $96 \%$. In this study, there were 211 patients who would have been flagged by such a warning, of which less than $4 \%$ (8), went on to complete treatment.

In centres where the number of defaulters, and therefore the workload in tracing and trying to prevent defaulting would be less, a more sensitive indicator such as 'not taking four out of the first four doses' would be appropriate.

In conclusion, we found no factors recorded at registration which would help identify patients who would go on to become defaulters. Other studies have suggested associations between the factors chosen for study and non-compliant behaviour. This inconsistency only serves to highlight the complexity of the issue of non-compliance and the necessity for further qualitative research.

The study highlighted the very short time available to the health worker to present a 
message that might prevent defaulting, and the speed with which the treatment centre needs to react to a pattern of attendance which is predictive of defaulting. If a health education message in the clinic setting is chosen as the primary method of ensuring compliance, the message needs to be given and understood at the first or second clinic visit. For most patients, there will be other information that needs to be given at the same time. If patient compliance is seen as an important factor, then some traditional messages may need to be delayed to prevent overloading the patient at the first visit. All Health Education messages necessary must be given in this short time, this to enable the patient to understand his/her disease, its treatment and treatment procedure. The findings suggest the need to develop a patient education list, which structures which messages to give at which visit.

If a treatment centre is to introduce an early indicator of non-compliance, in order to highlight patients who need follow up outside of the clinic, then there is a balance between speed of getting the warning, sensitivity to maximize the number of defaulters targeted, positive predictive value to ensure that patients targeted or visited are really likely to become defaulters and the overall number of patients highlighted by the indicator.

The correct balance is different in each centre. Where the defaulting rate is very high, and the overall number of patients is high, then significant improvements might be achieved by targeting patients who fail to take at least two of the first three doses on time. In centres where the problem is less acute, a more sensitive indicator, such as failing to take all of the first four doses on time, may yield better results.

The issue of non-compliant behaviour is complex. The objectives of this study were simply to try to find indicators that would be operationally useful to highlight patients who might become defaulters, before they have lost all contact with the treatment centre. In this way, it is hoped that defaulting might be prevented, rather than waiting until defaulting has occurred, at which point finding the patient and motivating them to take treatment regularly would be more difficult. Only an indicator based on actual behaviour in the first few months showed any predictive capability in this study.

\section{Suggestions for further research}

This study shows how complex the concept of non-compliance is. To really understand noncompliance, a fuller understanding must be sought of all factors involved. A patient's willingness to comply depends also on his/her ability to comply! Because decisions to discontinue treatment are taken in the course of everyday life, qualitative research into what non-compliance means to the patients themselves is suggested; the patients' understanding of their experience with their disease and its treatment, as well as the divers situations in which they have them.

\section{References}

${ }^{1}$ Anandaraj H. Psycho social dimension of drug default in leprosy. Ind J Lepr, 1986; 58: 424-430.

2 Baral JP. National manual for leprosy control in Nepal. Kathmandu HMG Leprosy Control Division, 1993.

${ }^{3}$ Brakel WH van, Soldenhoff R de, McDougall AC. The allocation of leprosy patients into paucibacillary and multibacillary groups for multidrug therapy, taking into account the number of body areas affected by skin, or skin and nerve lesions. Lepr Rev, 1992; 63: 231-246.

${ }^{4}$ Gopalakrishnan S. Dropouts during treatment for leprosy. Ind J Lepr, 1986; 58: 431-440. 
5 Huikeshoven H. Patient compliance in leprosy control. A necessity in old and new regimens. Int J Lepr, 1985; 53: 475-480.

${ }^{6}$ Kannan N, Sivaram M. Variables influencing regularity of leprosy patients in attending treatment clinics. Ind $J$ Lepr, 1992; 64: 505-511.

7 Koticha KK, Patre BB, Nair PRR. Problems in urban leprosy control with special reference to case holding. Int $J$ Lepr, 1984; 52: 482-487.

8 Langhorne P, Duffus P, Berkely JS, Jesudasan K. Factors influencing clinic attendance during multidrug therpay of leprosy. Lepr Rev, 1986; 57: 17-30.

9 Myint T, Htoon MT, Win M, Yin C. Risk factors among defaulters in the urban leprosy control centre of Theketa Township in the city of Yangon, Myanmar 1986. Lepr Rev, 1992; 63: 345-349.

${ }^{10} \mathrm{Pal}$ S, Ramanathan U, Ramu G. Study of the cause of irregularity of patients attending the outpatient department of CJIL Agra. Ind J Lepr, 1985; 57: 607-612.

11 Ramanajah RBBSV, Jeyasingh P, Fernandes SD. Non-compliance to treatment among leprosy patients. Ind $J$ Lepr, 1986; 58: 96-105.

12 Vadher A, Lall jee M. Patient treatment compliance in leprosy: a critical review (editorial). Int J Lepr, 1992; 60: 587-607. 